\title{
The Control Design for Trajectory Tracking of Four- wheeled Mobile Robot using Model Predictive Control: A Preliminary Study
}

\author{
Dimas Maulana \\ Department of Mathematics \\ Universitas Negeri Surabaya \\ Indonesia \\ dimasmaulana@unesa.ac.id
}

\author{
Yusuf Fuad \\ Department of Mathematics \\ Universitas Negeri Surabaya \\ Indonesia \\ yusuffuad@unesa.ac.id
}

\author{
Yuliani Puji Astuti \\ Department of Mathematics \\ Universitas Negeri Surabaya \\ Indonesia \\ yulianipuji@unesa.ac.id
}

\begin{abstract}
The mobile robot is one of the Unmanned Vehicle that belongs to Unmanned Ground Vehicle (UGV) which has the ability to be remotely controlled. The advancement in navigation has enabled new opportunity to send the UGV to explore new area or disaster mitigation. The path is set with the help of digital imaging of a certain area, then the mobile robot is expected to follow the path. In this paper, we conduct a simulation of fourwheeled mobile robot trajectory tracking. We design a control for trajectory tracking using the Model Predictive Control approach. By simulating for some values of control and reference, the simulation shows that the control design for the trajectory tracking in four wheeled mobile robots need some improvement.
\end{abstract}

Keywords-model predictive control, mobile robot, trajectory tracking

\section{INTRODUCTION}

The Unmanned Vehicles (UV) are frequently used by the military or civilian to do the surveillance, investigation, or exploration to either inaccessible, inexplorable, or dangerous area. The UV such as the Unmanned Aerial Vehicle (UAV), Unmanned Underwater Vehicle (UUV), Unmanned Spacecraft Vehicle (USV), Unmanned Surface Vehicle and Unmanned Ground Vehicle have the ability to be remotely controlled or even self-driven are beneficial to human being, in terms of minimising risk. [1] Picking some extra-terrestrial stone is one of the examples of using mobile robots. [2]

The mobile robot is one of unmanned ground vehicle which can be tracked when it is applied with Global Positioning System (GPS). The advancement in navigation plays a significant role in military technology. The GPS utilisation has enabled new opportunity to explore new area for natural resources or even disaster mitigation. Scientists define the trajectory from the digital imaging to overcome the obstacles in the path, then the mobile robot is set to follow the rule.

The trajectory tracking has been studied by some researcher in recent years. Tawfik [3] and Carlucho et all [4] has been conducted the optimal trajectory tracking in mobile robot using Proportional Integral Derivative, while Villacr et al were using Sliding Mode Control to control the mobile robot [5]. Model Predictive Controller is also applicable in mobile robot trajectory tracking, recent research has been done by Kanjawaniskul [6] and Liu [7]. In this paper, we conduct a design control of mobile robot

\section{PROBLEM Formulation}

\section{A. Kinematics}

One of the types of mobile robot is having an actuator. An actuator is a device Thus, the mobile robot can move freely

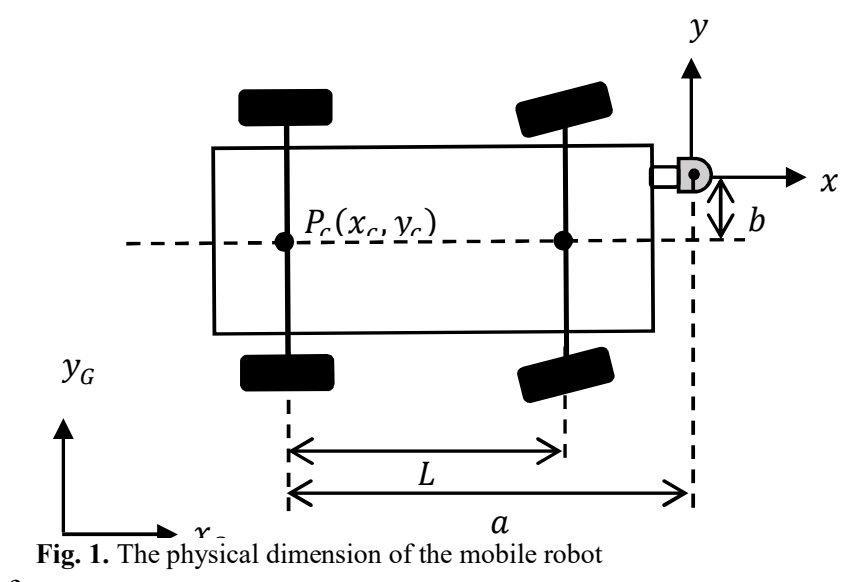
from 
a point to another in the ground. In this paper, we used a fourwheeled mobile robot which able to move freely in the ground [2].

In this paper, the GPS is attached in the front left of the mobile robot. The front wheels are capable to do a maximum 30 degrees left-and-right turn to move along the trajectory. The rear wheels are remained fixed. The mobile robot moves in X$\mathrm{Y}$ axis. The robot is assumed to only move forward and the path is determined first. The illustration for the mobile robot is shown in Error! Reference source not found.

When the robot is moving, the steering system is shown below in Error! Reference source not found.

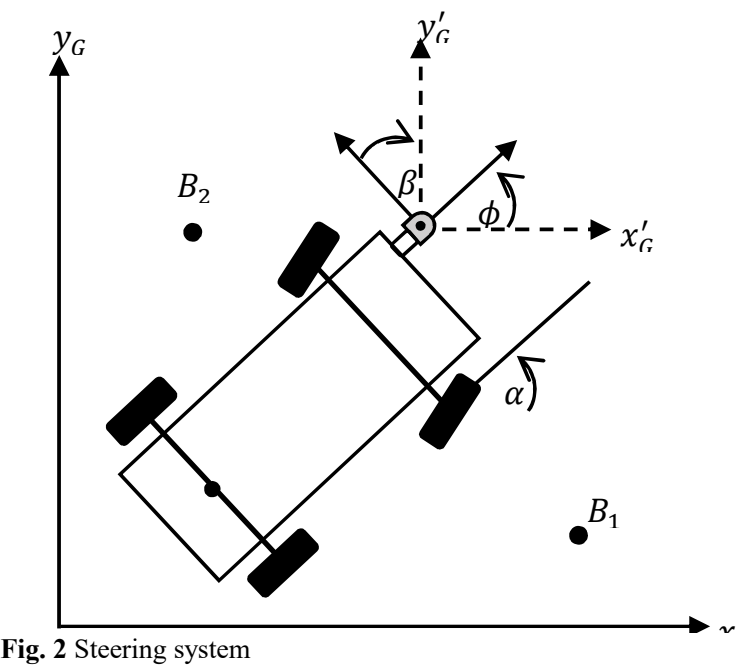

B. Mathematical Model

In this case, the model is nonlinear and discrete. The model is modified from [8]. The model is:

$$
\left[\begin{array}{c}
\dot{x} \\
\dot{y} \\
\dot{\phi}
\end{array}\right]=\left[\begin{array}{c}
v \cos (\phi)-\frac{v}{L}(a \sin (\phi)+b \cos (\phi)) \tan (\alpha) \\
v \sin (\phi)+\frac{v}{L}(a \cos (\phi)-b \sin (\phi)) \tan (\alpha) \\
\frac{v}{L} \tan (\alpha)
\end{array}\right]
$$

Where

$x, y$ : The mobile robot position relative to the GPS coordinate system

$\phi$ : The angle of mobile robot

$v$ : The velocity of mobile robot

$\alpha \quad$ : The steering angle of mobile robot

Some constants are given by Table 1

TABLE 1 CONSTANT TABLE

\begin{tabular}{|c|l|c|}
\hline Constants & \multicolumn{1}{|c|}{ Terminology } & Value \\
\hline$L$ & $\begin{array}{l}\text { The distance between front wheels and rear } \\
\text { wheels }\end{array}$ & $2,5 \mathrm{~m}$ \\
\hline$a$ & $\begin{array}{l}\text { The distance between the mobile robot's } \\
\text { rear centre point and the GPS. }\end{array}$ & $1,25 \mathrm{~m}$ \\
\hline$b$ & $\begin{array}{l}\text { The distance between mobile robot's centre } \\
\text { point and GPS. }\end{array}$ & 0 \\
\hline
\end{tabular}

By taking $x=x_{1}, y=x_{2}$, and $\phi=x_{3}$ respectively, the model can be rewritten as

$$
\left[\begin{array}{l}
x_{1} \\
x_{2} \\
x_{3}
\end{array}\right]=\left[\begin{array}{c}
v \cos \left(x_{3}\right)-\frac{v}{L}\left(a \sin \left(x_{3}\right)+b \cos \left(x_{3}\right)\right) \tan (\alpha) \\
v \sin \left(x_{3}\right)+\frac{v}{L}\left(a \cos \left(x_{3}\right)-b \sin \left(x_{3}\right)\right) \tan (\alpha) \\
\frac{v}{L} \tan (\alpha)
\end{array}\right]
$$

We will control the velocity and the steering angle of mobile robot, thus the control is

$$
\mathbf{u}=\left[\begin{array}{l}
v \\
\alpha
\end{array}\right]
$$

We can also rewrite (2) and (3) in more compact form

$$
\dot{\mathbf{x}}=f(\mathbf{x}, \mathbf{u})
$$

A linear model is obtained by computing an error model with respect to a reference mobile robot. Thus, the trajectory reference can be written as:

$$
\dot{\mathbf{x}}_{r}=f\left(\mathbf{x}_{r}, \mathbf{u}_{r}\right)
$$

By expanding (4) around $\left(\mathbf{x}_{r}, \mathbf{u}_{r}\right)$ in Taylor Series and truncating the higher order terms, we will obtain:

$$
\dot{\mathbf{x}} \approx f\left(\mathbf{x}_{r}, \mathbf{u}_{r}\right)+f_{\mathbf{x}, r}\left(\mathbf{x}-\mathbf{x}_{r}\right)+f_{\mathbf{u}, r}\left(\mathbf{u}-\mathbf{u}_{r}\right)
$$

Where $f_{\mathbf{x}, r}$ and $f_{\mathbf{u}, r}$ are the Jacobian of $f$ with respect to $\mathbf{x}$ and $\mathbf{u}$. By subtracting (6) and (5) we have:

$$
\dot{\mathbf{x}}-\dot{\mathbf{x}}_{r} \approx f_{\mathbf{x}, r}\left(\mathbf{x}-\mathbf{x}_{r}\right)+f_{\mathbf{u}, r}\left(\mathbf{u}-\mathbf{u}_{r}\right)
$$

because $\widetilde{\mathbf{x}} \triangleq \mathbf{x}-\mathbf{x}_{r}$ and $\widetilde{\mathbf{u}} \triangleq \mathbf{u}-\mathbf{u}_{r}$, we can rewrite (7) as

$$
\tilde{\dot{\mathbf{x}}} \approx f_{\mathbf{x}, r} \tilde{\mathbf{x}}+f_{\mathbf{u}, r} \widetilde{\mathbf{u}}
$$

Therefore, the forward difference gives the following discrete-time linear model

$$
\mathbf{x}(k+1)=\mathbf{A}(k) \mathbf{x}(k)+\mathbf{B}(k) \mathbf{u}(k)
$$

With

$$
\begin{gathered}
\mathbf{A}(k)=\left[\begin{array}{ccc}
1 & 0 & v(k) x_{3}(k) \Delta t-\frac{v(k)}{2} \tan (\alpha(k)) \Delta t \\
0 & 1 & v(k) \Delta t-\frac{v(k)}{2} x_{3}(k) \tan (\alpha(k)) \Delta t \\
0 & 0 & 1
\end{array}\right] \\
\mathbf{B}(k)=\left[\begin{array}{ccc}
\cos \left(x_{3}(k)\right) \Delta t-\frac{\alpha(k)}{2} \sin \left(x_{3}(k)\right) \Delta t & -\frac{v(k)}{2} \sin \left(x_{3}(k)\right) \Delta t \\
\sin \left(x_{3}(k)\right) \Delta t+\frac{\alpha(k)}{2} \cos \left(x_{3}(k)\right) \Delta t & \frac{v(k)}{2} \cos \left(x_{3}(k)\right) \Delta t \\
\frac{2}{5} \alpha(k) \Delta t & \frac{2}{5} v(k) \Delta t
\end{array}\right]
\end{gathered}
$$

\section{Model PREDICTIVE CONTROL}

\section{A. Optimisation Problem}

The control rule is defined by

$$
\tilde{\mathbf{x}}(k)=\mathbf{x}(k)-\mathbf{x}_{r}(k)
$$

We also define an objective function [9]:

$$
\bar{J}^{\prime}(k)=\frac{1}{2} \overline{\mathbf{u}}^{T}(k) \mathbf{H}(k) \overline{\mathbf{u}}(k)+\mathbf{f}^{T}(k) \overline{\mathbf{u}}(k)
$$


With

$$
\begin{aligned}
& \mathbf{H}(k) \triangleq 2\left(\overline{\mathbf{B}}^{T}(k) \overline{\boldsymbol{Q}} \overline{\mathbf{B}}(k)+\mathcal{R}\right) \\
& \mathbf{f}(k) \triangleq 2 \overline{\mathbf{B}}^{T}(k) \overline{\boldsymbol{Q}} \overline{\mathbf{A}}(k) \tilde{\mathbf{x}}(k \mid k) \\
& \mathbf{d}(k) \triangleq \tilde{\mathbf{x}}^{T}(k \mid k) \overline{\mathbf{A}}^{T}(k) \overline{\boldsymbol{Q}} \overline{\mathbf{A}}(k) \tilde{\mathbf{x}}(k \mid k)
\end{aligned}
$$

Where $\mathbf{H}$ is Hessian Matrix, $Q$ is the weighted matrix of the state space, and $R$ is the weighted matrix of the control. The optimisation problem could be stated as finding the value of $\widetilde{\mathbf{u}}^{*}$, so that:

$$
\widetilde{\mathbf{u}}^{*}=\arg \min _{\widetilde{\mathbf{u}}}\{J(k)\}
$$

We need to constraint the input control to make the performance good, we define a constraint for input control at k-th iteration [10].

$$
\mathbf{u}_{\min } \leq \widetilde{\mathbf{u}}(k+j \mid k) \leq \mathbf{u}_{\max }
$$

With $j$ is satisfied by $j \in[0, N-1]$.

\section{B. Linear MPC Algorithm}

The algorithm is given by this block diagram [9]:

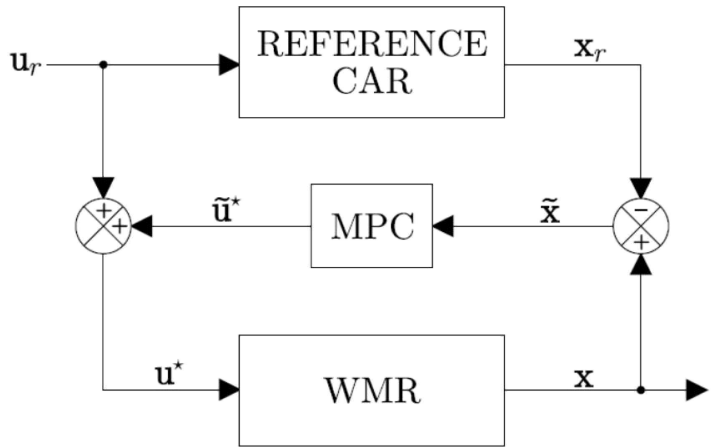

Fig. 3 Block diagram

At time $t$, we do:

Step 0 Input the $\mathbf{x}_{\mathrm{r}}(0), \mathbf{u}_{\mathrm{r}}(0)$ dan $\mathbf{x}(0) . \mathbf{x}_{\mathrm{r}}(0)$

Step 1 For $\mathrm{N}<10$, do:

Step 2 Calculate $\tilde{\mathbf{x}}(\mathrm{k})=\mathbf{x}(\mathrm{k})-\mathbf{x}_{\mathrm{r}}(\mathrm{k})$

Step 3 Solve the optimisation problem

Step 4 Obtain $\mathbf{u}^{*}(\mathrm{k})=\widetilde{\mathbf{u}}^{*}(\mathrm{k})+\mathbf{u}_{\mathrm{r}}(\mathrm{k})$

Step 5 Obtain the mobile robot position at $\mathrm{k}+1$

Step 6 Obtain the reference at the step $k$

Step 7 Plot the reference

Step 8 Update the trajectory at the step $k$

Step 9 Plot the trajectory

\section{RESUlT AND DiscUSSION}

We choose $Q$ and $R$ as follow:

$$
Q=R=\left[\begin{array}{ccccc}
0.01 & 0 & 0 & \cdots & 0 \\
0 & 0.01 & 0 & \cdots & 0 \\
0 & 0 & 0.01 & \cdots & 0 \\
\vdots & \vdots & \vdots & \ddots & \vdots \\
0 & 0 & 0 & \cdots & 0.01
\end{array}\right]
$$

By using MATLAB, for $\mathbf{x}_{\mathbf{r}}(0)=[0,0,0]^{T}, \mathbf{u}=[0.5,0]^{T}$ and $\mathbf{x}(0)=[0,0,0]^{T}$, the graph is shown in
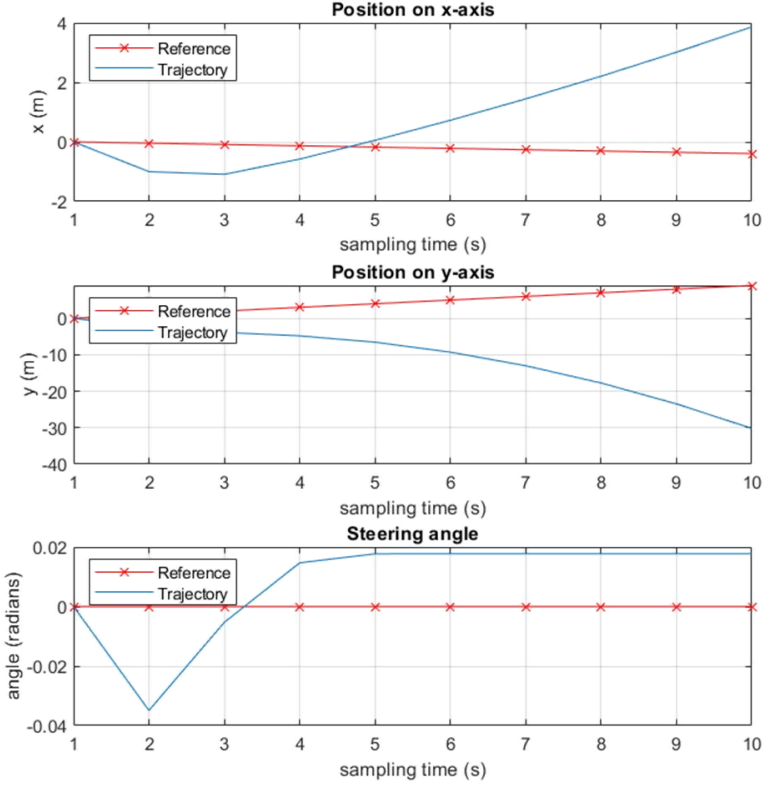

Fig. 4 Simulation result for $\mathbf{x}_{\mathrm{r}}(\mathbf{0})=[0,0,0]^{T}, \mathbf{u}=\left[0.5, \mathbf{q}^{T}\right.$ and $\mathbf{x}(0)=$ $[0,0,0]^{T}$

It is shown that the design control for the three states still need to be improved, we will try to test the design control by the different input, for the next trial, we use for $\mathbf{x}_{\mathbf{r}}(0)=$ $[0,0,10]^{T}, \mathbf{u}=\left[0.5, \frac{\pi}{12}\right]^{T}$ and $\mathbf{x}(0)=[0,0,10]^{T}$
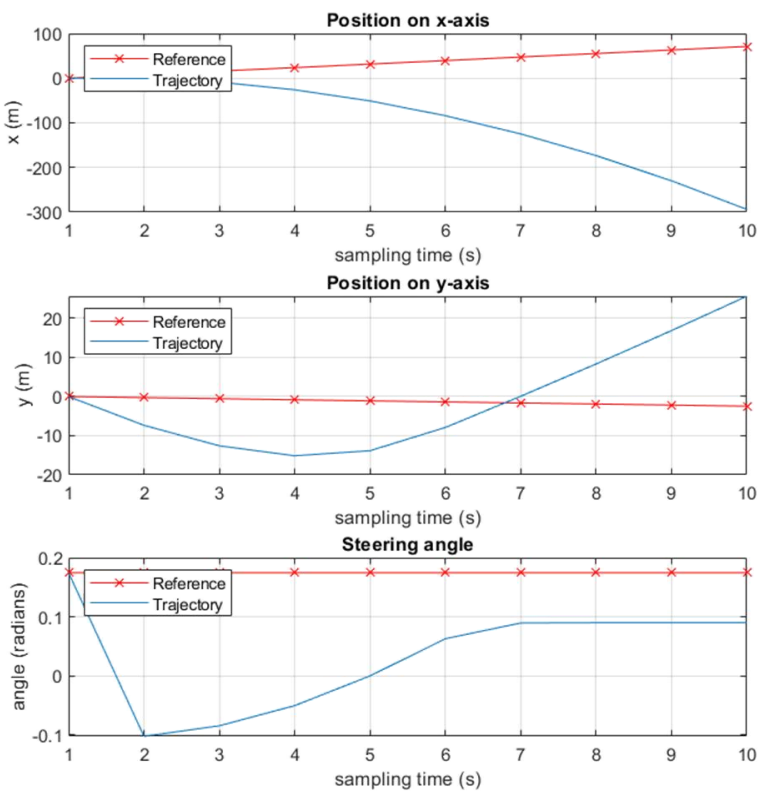

Fig. 5 Simulation result for $\mathbf{x}_{\mathrm{r}}(\mathbf{0})=[0,0,10]^{T}, \mathbf{u}=\left[0.5 \frac{\pi}{12}\right]^{T}$ and $\mathbf{x}(\mathbf{0})=$ $[\mathbf{0 , 0}, \mathbf{1 0}]^{T}$ 
For the last simulation, we will try for $\mathbf{x}_{\mathbf{r}}(0)=$ $[-1,-1,5]^{T}, \mathbf{u}=\left[0.5, \frac{\pi}{9}\right]^{T}$ and $\mathbf{x}(0)=[0,0,5]^{T}$ and we obtain:
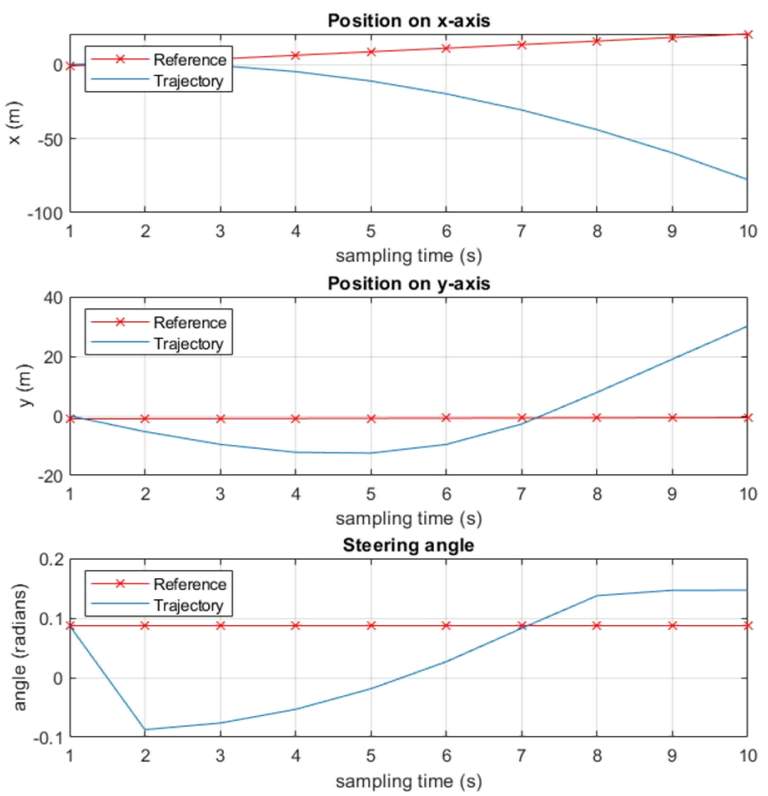

Fig. 6 Simulation result for $\mathbf{x}_{\mathrm{r}}(\mathbf{0})=[-\mathbf{1},-\mathbf{1}, 5]^{T}, \mathbf{u}=\left[0.5 \frac{\pi}{9}\right]^{T}$ and $\mathbf{x}(\mathbf{0})=[\mathbf{0}, \mathbf{0}, 5]^{T}$

From the simulation we can see that the control design still needs an improvement.

\section{ACKNOWLEDGMENT}

The authors would like to thank FMIPA Unesa for the Penelitian Kebijakan FMIPA Tahun Anggaran 2018 grant

\section{REFERENCES}

[1] D. A. Maulana, 'Penerapan Model Predictive Control MPC Pada Desain Pengendalian Robot Mobil Beroda Empat', J. Zeta, vol. 3, no. 2, pp. 46-51, 2017.

[2] M. I. Rusydi, 'Perancangan dan Implementasi Pengendali PID pada Subsistem Aktuator Robot Mobil Tipe Sinkron', vol. 2, no. 29, pp. 43-48, 2008.

[3] M. A. Tawfik, E. N. Abdulwahb, and S. M. Swadi, 'Optimal Trajectory Tracking Control for a Wheeled Mobile Robot Using Fractional Order PID Controller', J. Univ. Babylon Eng. Sci., vol. 26, no. 4, pp. 292-306, 2018.

[4] I. Carlucho, M. De Paula, S. A. Villar, and G. G. Acosta, 'Incremental Q-learning Strategy for Adaptive PID Control of Mobile Robots', Expert Syst. Appl., vol. 80, pp. 183-199, 2017.

[5] J. Villacr, M. Herrera, and N. Sotomayor, 'A Fuzzy Sliding Mode Controller from A Reduced Order Model: A Mobile Robot Experimental Application', in 4th International Conference on Control, Decision and Information Technologies (CoDIT), 2017, vol. 1, no. 1, pp. 674-678.

[6] K. Kanjanawaniskul, 'Motion Control of a Wheeled Mobile Robot Using Model Predictive Control: A Survey', Asia-Pacific J. Sci. Technol., vol. 17, no. 5, pp. 811-837, 2012.

[7] C. Liu and J. K. Hedrick, 'Model Predictive Control-based Target Search and Tracking using Autonomous Mobile Robot with Limited Sensing Domain', Proc. Am. Control Conf., pp. 2937-2942, 2017.

[8] S. Rezaei and R. Sengupta, 'Kalman Filter-based Integration of DGPS and Vehicle Sensors for Localization', IEEE Trans. Control Syst. Technol., vol. 15, no. 6, pp. 1080-1088, 2007.

[9] F. Kühne, W. F. Lages, and J. M. Gomes da Silva Jr, 'Model Predictive Control of a Mobile Robot using Linearization', Proc. Mechatronics Robot. 2004, Aa-chen, Ger., pp. 525-530, 2004.

[10] L. Wang, Model Predictive Control System Design and Implementation Using MATLAB. 2009. 